\title{
Environmental and genetic influences on mating strategies along a replicated food availability gradient in guppies (Poecilia reticulata)
}

\author{
Gita R. Kolluru • Gregory F. Grether • Heidy Contreras
}

\begin{abstract}
Food availability is expected to influence the relative cost of different mating tactics, but little attention has been paid to this potential source of adaptive geographic variation in behavior. Associations between the frequency of different mating tactics and resource availability could arise because tactic use responds directly to food intake (phenotypic plasticity), because populations exposed to different average levels of food availability have diverged genetically in tactic use, or both. Different populations of guppies (Poecilia reticulata) in Trinidad experience different average levels of food availability. We combined field observations with laboratory "common garden" and diet experiments to examine how this environmental gradient has influenced the evolution of male mating tactics. Three independent components of variation in male behavior were found in the field: courtship versus foraging, dominance interactions, and interference competition versus searching for mates. Compared with low-food-availability sites, males at high-foodavailability sites devoted more effort to interference competition. This difference disappeared in the common garden experiment, which suggests that it was caused by phenotypic plasticity and not genetic divergence. In the diet experiment, interference competition was more frequent and intense among males raised on the greater of two food levels, but this was only true for fish descended from sites with low food availability. Thus, the association between interference competition and food availability in the field can be attributed to a genetically variable norm of reaction.
\end{abstract}

Genetically variable norms of reaction with respect to food intake were found for the other two behavioral components as well and are discussed in relation to the patterns observed in the field. Our results indicate that food availability gradients are an important, albeit complex, source of geographic variation in male mating strategies.

Keywords Mating tactic $\cdot$ Resource availability . Geographic variation · Intrasexual competition .

Dominance $\cdot$ Phenotypic plasticity .

Genotype by environment interaction

\section{Introduction}

Intraspecific variation in mating strategies is well documented in a variety of taxa (Gross 1996; Foster and Endler 1999; Brockmann 2001; Shuster and Wade 2003). However, only a few studies have linked geographic variation in alternative mating behaviors to specific environmental factors other than predation intensity (e.g., Carroll 1993; Carroll and Corneli 1995). Food intake is particularly important in influencing mating behavior (Blanckenhorn et al. 1995; Belovsky et al. 1996; Plaistow and Siva-Jothy 1996; Moczek and Emlen 1999), and food availability gradients offer excellent opportunities to study geographic variation in mating tactics (Carroll and Corneli 1999). A key step to understanding variation along environmental gradients is determining whether the differences among 
populations represent phenotypic plasticity or local genetic adaptation (Carroll and Corneli 1999; Foster and Endler 1999; Weitere et al. 2004). In this paper, we use a combination of field observations and common-environment lab experiments to tease apart these alternatives in guppies (Poecilia reticulata).

Guppies are a classic system for studies of geographic variation in behavior (Houde and Endler 1990; Endler 1995; Houde 1997). Grether et al. (1999, 2001) documented a replicated food availability gradient among lowpredation guppy streams in Trinidad. Low-predation streams contain no piscivorous fish except Rivulus hartii, which only occasionally eats guppies and preys mainly on juveniles (Endler 1978, 1995). The main source of food for guppies in these streams is attached unicellular algae (Dussault and Kramer 1981), the abundance of which is largely a function of forest canopy cover. Sites that receive more light have larger standing crops of algae, but not correspondingly higher densities of guppies, than sites within the same drainage that receive less light (Grether et al. 2001). In the high-light, high-food-availability sites, female and juvenile guppies grow faster and males mature at larger asymptotic sizes than their counterparts in the lowfood-availability sites (Grether et al. 2001).

The mating tactics of male guppies, in increasing order of presumed energetic investment, include sneaking copulations without courtship display, displaying to females before copulation (courtship), and aggressively inhibiting rival males (Rodd and Sokolowski 1995; Houde 1997; Jirotkul 2000; Kelly and Godin 2001). Male-male aggression occurs in two basic contexts, which, for brevity, we call "competition" and "dominance" (Kolluru and Grether 2005). "Competition" refers to interference between males simultaneously attempting to court the same female, whereas "dominance" refers to aggressive interactions between males out of the immediate proximity of females. The latter may serve to establish or maintain dominance relationships with respect to priority of access to receptive females.

In this paper, we present results from an extensive survey of behavioral variation across ten guppy sites in the Northern Range of Trinidad. Sites were chosen to represent the available extremes in forest canopy cover, and hence food availability, among low-predation streams, and were classified as either "high" or "low" with respect to food availability, using previously established criteria (see Materials and methods). Detailed behavioral (focal) observations were carried out on individual males at each site and recorded along with data on local conditions (sex ratio, fish density, and light level). Offspring of wild-caught females were raised under "common garden" conditions in the laboratory and observed in mixed-sex tanks under standardized conditions after reaching sexual maturity. Four of the ten populations were included in an experiment on the effects of lifetime food intake on male mating tactics. Results from the latter experiment have been published (Kolluru and Grether 2005) but are reanalyzed here for comparison to the field observations.

We predicted that males in high-food-availability sites would engage in energetically-demanding (aggressive) mating tactics more frequently than males in low-foodavailability sites. If the field differences between low- and high-food-availability sites were due to phenotypic plasticity, then any phenotypic differences between low- and highfood-availability sites in the field should largely disappear in the lab. Alternatively, the differences may persist in the lab-reared males, suggesting that the field differences are due to genetic divergence between low- and high-foodavailability sites. A third possibility is that the extent to which behavior is flexible in response to food intake varies among populations (genotype by environment interaction; Thompson 1999). Environmental factors other than food availability may also influence mating strategies in the wild. Light levels, density, and sex ratio have been shown to influence guppy mating tactics (Reynolds et al. 1993; Houde 1997; Jirotkul 1999a,b, 2000; Gamble et al. 2003). Our main objective in this paper is to examine each of these possible influences on geographic variation in the mating tactics of guppies and evaluate their relative importance.

\section{Materials and methods}

\section{Study sites}

Study sites meeting the following criteria were chosen during a survey of stream drainages conducted in 1996 and 2000: (1) intact primary or old secondary growth rainforest; (2) relatively homogeneous forest canopy cover within sites; (3) separated from each other by multiple barriers to guppy dispersal, including two or more waterfalls; and (4) no predatory fish except $R$. hartii. We chose one stream with relatively low canopy openness and another with relatively high canopy openness in each of five phylogenetically distinct drainages, representing two major drainage systems. This sampling design helps to control for phylogenetic effects to the extent that sites within one drainage are closer to each other genetically than sites in different drainages, as would be expected from the dispersal mode of guppies. The five drainages (Fig. 1) occur in two drainage systems, the Oropuche (the four Quare streams), which empties into the Atlantic Ocean, and the North Slope (the remaining six streams), which empties into the Caribbean Sea. Previous studies have demonstrated that the populations in these two drainage systems are genetically distinct (reviewed by Houde 1997, p. 15). 


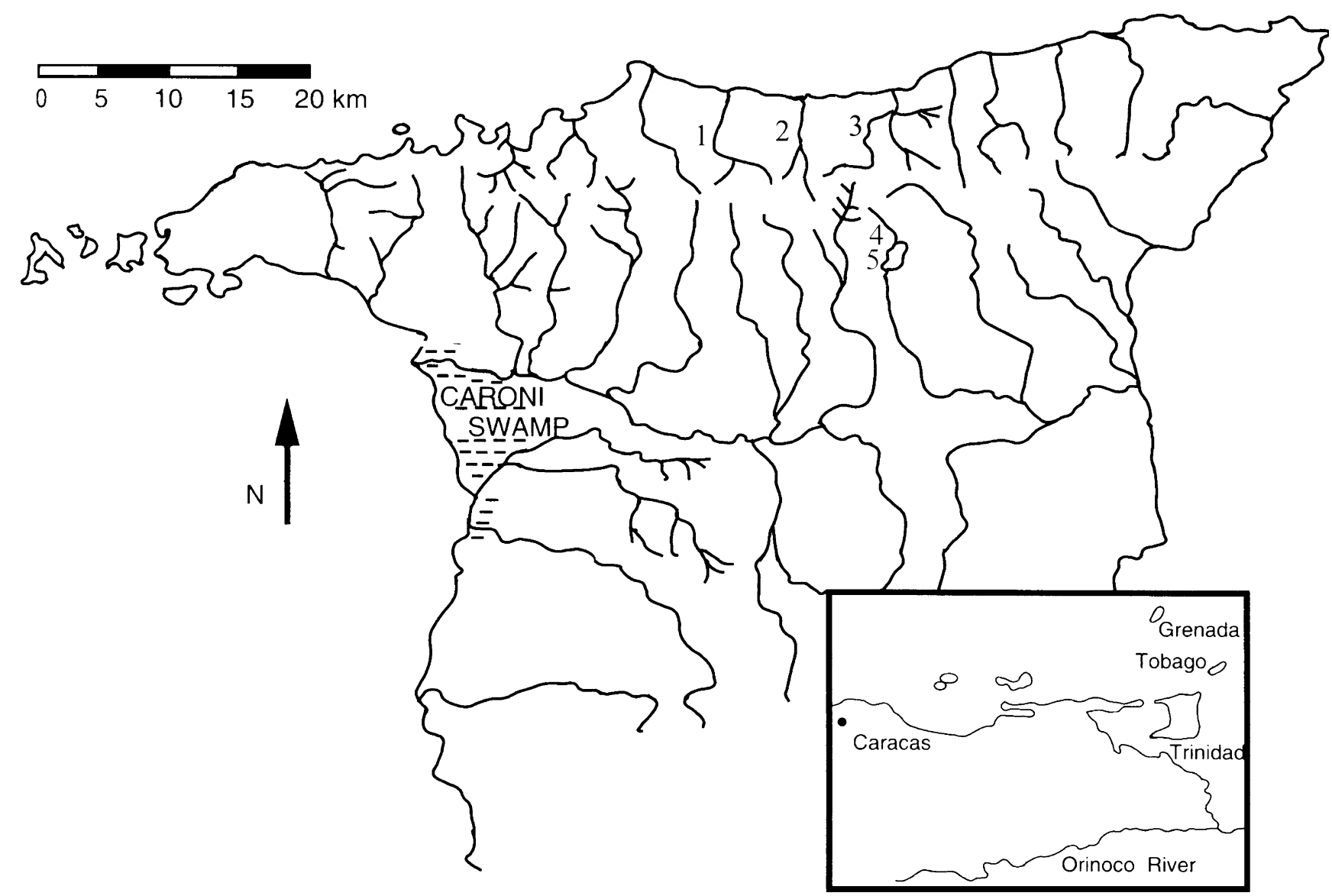

Fig. 1 Field sites in the Northern Range of Trinidad. The drainages, site names, lab experiment numbers, food availability levels, and Universal Transverse Mercator Grid coordinates (Zone 20) are as follows: (1) Marianne drainage: Marianne River (Experiment I, high food availability, PS 858 895); Marianne Tributary (Experiment I, low food availability, PS 842 894). (2) Paria drainage: Paria River (Experiment I, high food availability, PS 911 920); Paria Tributary (Experiment I, low food availability, PS 895 907). (3) Madamas

\section{Field behavior observations}

Focal observations were conducted in April-May 2000 at three times of day: early (0700 to 1000), mid (1000 to 1400 ), and late (1400 to 1800). Food availability differences between streams persist throughout the year (Grether et al. 2001); however, we conducted observations during the dry season so that we could follow individual fish without interference from rain. Focal males were selected haphazardly and distinguished from others based on readily visible color patterns. Observations were made by sitting quietly next to the stream and tape recording behaviors for 5 min or until visual contact with the male was lost (male guppies usually display more than once per minute; see Magurran and Seghers 1994 for similar methods). We recorded the light level [photosynthetically active radiation, $\left.\log _{10}\left(\mu \mathrm{mol} \mathrm{m} \mathrm{m}^{-2} \mathrm{~s}^{-1}\right)\right]$ using a quantum radiometer (Licor drainage: Aqui River (Experiment II, high food availability, PS 939 887); Madamas Tributary (Experiment II, low food availability, PS 950 880). (4) Upper Quare drainage: Small Crayfish River (Experiment II, high food availability, PS 965 835); Large Crayfish River (Experiment II, low food availability; 965 832). (5) Lower Quare drainage: Quare 1 (Experiment I, high food availability, PS 970 806); Quare 2 (Experiment I, low food availability, PS 969 809). The map is modified from Houde (1997) with permission from A. E. Houde.

LI-189) over the portion of the stream where the focal observation took place and noted the number of mature males and females within approximately $1 \mathrm{~m}$ surrounding the focal male during the majority of the focal observation (based on visual observation). We observed 1-5 focal males per pool, 6-26 pools per site, and 58-145 males per site (964 focal males in total).

\section{Lab behavior observations}

We performed two types of lab behavior experiments, which we refer to as the "common garden" and "diet" experiments. The common garden experiment involved the same ten sites that were studied in the field and was designed to determine whether variation between site types (low- versus high-food-availability sites) is due to phenotypic plasticity or to fixed genetic differences in response to 
food availability. Some of the data for this lab study were obtained from Kolluru and Grether (2005; high food level males). All of the males in this study were raised on either the high food level from Kolluru and Grether (2005) or on ad libitum food, and the details of this study are given below. The diet experiment consisted of reanalysis of data originally published in Kolluru and Grether (2005) and was designed to determine whether males from low- and highfood-availability sites differ in their behavioral norms of reaction to food intake. For this study, the males from each of four sites (two low- and two high-food-availability) were raised on one of two food levels, low or high. Comparison of the asymptotic sizes of wild-caught males from low- and high-food-availability sites with males from the lab food treatments demonstrated that the low food level is on the low end of the range that guppies typically experience in the wild and the high food level is in the middle of the range (Kolluru et al. 2006). The methods for behavioral observations were identical to those employed in the common garden experiment.

\section{Common garden experiment}

For this experiment, we combined data from two separate lab experiments, one with six sites (Experiment I) and one with four sites (Experiment II). Together, these encompassed all ten of the sites for which we collected field data (see Fig. 1). The lab populations were housed either at the University of California, Santa Barbara (Experiment I) or at the University of California, Los Angeles (Experiment II). In Experiment I, the fish were housed in a shaded greenhouse and thus exposed to indirect sunlight. In Experiment II, the fish were housed in a windowless room. In both labs, water temperature was maintained at $24 \pm 2^{\circ} \mathrm{C}$ and a 12:12 photoperiod was simulated using mixed incandescent and daylight spectrum fluorescent lights. To maximize the genetic diversity of fish used in the experiment, we obtained offspring from 15 to 35 wild females per site. This represents a potentially much larger number of sires, because females mate multiply in the wild and can store sperm for up to 8 months (Winge 1937). To prevent the guppies from eating algae, we treated the water in the aquaria with 2-chloro-4, 6-bis-(ethylamino)-s-triazine (Algae Destroyer, Aquarium Pharmaceuticals) and removed visible algae regularly.

Wild-caught females and their offspring were housed as described in Grether (2000) and Kolluru and Grether (2005). Food amounts for males in both experiments were adjusted to the age and density of fish in the tank. In Experiment I, the fish were fed flake food to satiation [detailed protocol in Grether (2000)]. In Experiment II, the fish were fed twice daily (once daily on weekends) using a specially designed feeding device that delivered precise quantities of ground flake food to each tank. The food consisted of a mixture of spray-dried white fishmeal $(41.8 \%)$, wheat flour $(47 \%)$, vegetable oil $(2.0 \%)$, vitamin premix $(1.0 \%)$, and gelatin $(8.1 \%)$. The estimated protein content was $40 \%$, and the fat content was $10 \%$ (Lamon 2001, personal communication). Further details about the feeding protocol can be found in Kolluru and Grether (2005). The fish used for behavioral observations in Experiment I were second generation lab-born, and fish used in Experiment II were first generation lab-born. After being sexed under a dissecting microscope, males were housed in 8-1 tanks at densities of $1-4$ males per tank, and females were housed in 38-1 tanks at densities of 20 females per tank. Housing density did not affect male behavior in Experiment II (Kolluru and Grether 2005). To allow males to have courtship experience, we housed one mature stock female in each male tank for at least 1 week before behavioral observations. Females remained virgins until they were used in observations.

We used an open-aquarium design in which the fish could interact directly (Houde 1997), allowing us to simultaneously examine aggressive, courtship, and foraging behavior. Observations were conducted in 120-1 (Experiment I) and 180-1 (Experiment II) aquaria with natural, multicolored gravel bottoms and plastic bubblers connected to undergravel filters in windowless rooms maintained on the same light/dark schedule as the respective labs. The observation aquaria were covered with brown paper on three sides, and observations were made from the fourth side. Each aquarium was illuminated from the top with one daylight-spectrum fluorescent tube. Otherwise, the room was dark to maximize the visibility of the fish to the observer and to minimize the visibility of the observer to the fish.

To minimize the effects of competition for food (Magurran and Seghers 1991), we fed the fish to satiation twice per observation day and regularly removed visible algae from the observation aquaria. We filtered the water in the aquaria using a high-flow-rate charcoal canister filter (Marineland Magnum 350 convertible canister filter, Moorpark, CA) after each set of observations to minimize chemical effects on the behavior of fish in subsequent observations. To avoid artificially inflating male-male aggression, we used an even sex ratio (3:3), very low densities of fish per observation tank, and males that had not been housed together (see Houde 1997; Grether 2000). We also minimized body size disparities within male and female groups.

Behavior observations began within $2 \mathrm{~h}$ after the lights came on and were concluded within $4 \mathrm{~h}$ after the lights came on. A trial was initiated by releasing the three males chosen for testing into the observation aquarium after their color patterns were sketched. Males were chosen based on 
body size similarities and not based on color patterns. Females were released into the observation aquarium shortly after the males. The fish were then fed. On the following morning, the fish were fed again, and the first observation session began at least $15 \mathrm{~min}$ after the feeding. We performed at least three replicate focal samples of $5 \mathrm{~min}$ per male (with additional replicates added if a male did not perform courtship displays in at least two of the initial three replicates), alternating between males in a predetermined, random order. A minimum of $20 \mathrm{~min}$ elapsed between consecutive focal samples on a given male, and fish were fed again after the second sample (see Kolluru and Grether 2005 for additional details). We conducted lab observations on 374 males (Marianne drainage, 72; Paria drainage, 72; Madamas drainage, 78; Upper Quare drainage, 69; Lower Quare drainage, 83) and an equal number of females. Immediately following their use in observations, males and females were weighed to the nearest $0.1 \mathrm{mg}$, and their standard length was measured using digital calipers to the nearest $0.01 \mathrm{~mm}$.

\section{Behavior variables}

We recorded the following variables: time spent foraging, competing (two or more males simultaneously following or displaying to the same female) and swimming (including time spent searching for mates), courtship display rate, sneak copulation rate (forced copulation attempts not preceded by a display, in which gonopodial contact with the female's ventral surface was visible), escalated competition rate (competitions including chases and/or bites between males), dominance interaction rate (supplanting, displaying, chasing, or biting directed from one male to another while neither was following or courting a female), and escalated dominance interaction rate (dominance interactions including chases and/or bites between males).
Dominance interactions were usually distinctly one-sided, and thus one male could be classified as dominant and the other as subordinate. These measures of escalated competition and dominance are slightly different from those in Kolluru and Grether (2005). In that study, we reported the proportion of competition and dominance interactions that included escalations, rather than the frequency of escalated interactions, as we do here. Including the proportion variables would have resulted in too many missing values to perform a meaningful Principal Components Analysis (PCA; see below) because not all males were observed in competitive or dominance interactions.

\section{Data analysis}

All data were transformed to meet parametric assumptions, and all analyses were performed using JMP 3.2.2 (SAS Institute, Cary, NC). To extract independent components of variation from the field data, we performed PCA; Tabachnick and Fidell 2001). The field PCA yielded three components with eigenvalues $>1$, which explained $66.4 \%$ of the variation in behavior (Table 1). We interpreted the components based on the loadings (correlations between components and the original variables; Tabachnick and Fidell 2001) with absolute values greater than 0.5 (similar methods have been used in other studies; e.g., Reyer et al. 1998; Zuk et al. 1998). A varimax rotation, which maximizes high loadings and minimizes low loadings (Tabachnick and Fidell 2001), yielded components interpretable as "courtship vs foraging", "dominance", and "competition vs searching for mates". To use the field components of behavior to analyze the lab data, we first validated the approach by performing an independent PCA of the lab data, entering the same variables as for the field PCA. This PCA yielded four components with eigenvalues $>1.0$, that explained a total of $73.4 \%$ of the variation in the original data (Table 2). The
Table 1 PCA with varimax rotation of male $P$. reticulata behavior measured in the field $(N=925)$

\begin{tabular}{|c|c|c|c|}
\hline \multirow[t]{2}{*}{ Variable } & \multicolumn{3}{|l|}{ Component } \\
\hline & 1 (Courtship vs foraging) & 2 (Dominance) & $\begin{array}{l}3 \text { (Competition vs } \\
\text { searching for mates) }\end{array}$ \\
\hline Time foraging & -0.772 & 0.086 & -0.117 \\
\hline Time following females & 0.772 & 0.174 & 0.475 \\
\hline Time competing & 0.263 & 0.008 & 0.789 \\
\hline Time searching for mates & -0.244 & -0.211 & -0.713 \\
\hline Courtship display rate & 0.734 & 0.096 & 0.258 \\
\hline Sneak copulation rate & 0.320 & -0.149 & -0.138 \\
\hline Dominance interaction rate & 0.038 & -0.963 & 0.017 \\
\hline Escalated competition rate & -0.078 & -0.141 & 0.749 \\
\hline Escalated dominance rate & 0.025 & -0.960 & -0.033 \\
\hline Eigenvalue & 2.97 & 1.95 & 1.07 \\
\hline Explained variance $(\%)$ & 32.95 & 21.63 & 11.86 \\
\hline
\end{tabular}

Loadings $>|0.50|$ are shown in bold. 
Table 2 PCA with varimax rotation of male $P$. reticulata behavior measured in the lab $(N=374)$

\begin{tabular}{|c|c|c|c|c|}
\hline \multirow[t]{2}{*}{ Variable } & \multicolumn{4}{|l|}{ Component } \\
\hline & $\begin{array}{l}1 \text { (Dominance }+ \\
\text { escalated competition) }\end{array}$ & $\begin{array}{l}2 \text { (Courtship }+ \\
\text { competition vs foraging) }\end{array}$ & $\begin{array}{l}3 \text { (Courtship vs searching } \\
\text { for mates) }\end{array}$ & $\begin{array}{l}4 \text { (Sneak } \\
\text { copulations) }\end{array}$ \\
\hline Time foraging & -0.001 & -0.58 & 0.37 & 0.25 \\
\hline Time following females & 0.18 & 0.14 & -0.80 & 0.15 \\
\hline Time competing & -0.18 & 0.85 & 0.21 & 0.04 \\
\hline Time searching for mates & -0.003 & -0.04 & 0.79 & 0.08 \\
\hline Courtship display rate & -0.03 & 0.71 & -0.37 & 0.13 \\
\hline Sneak copulation rate & 0.02 & 0.007 & -0.03 & 0.95 \\
\hline Dominance interaction rate & -0.92 & 0.07 & 0.072 & 0.03 \\
\hline Escalated competition rate & -0.75 & 0.18 & 0.03 & -0.06 \\
\hline Escalated dominance rate & -0.94 & -0.06 & 0.086 & -0.008 \\
\hline Eigenvalue & 2.53 & 2.04 & 1.03 & 1.01 \\
\hline Explained variance (\%) & 28.06 & 22.63 & 11.48 & 11.23 \\
\hline
\end{tabular}

Loadings $>|0.50|$ are shown in bold.

lab PCA yielded similar components as those we obtained for the field, with the exception that a fourth axis consisting solely of sneak copulation rate emerged. Sneak copulation rate did not vary with site food availability in the lab $\left(F_{(1,249)}=3.86, P=0.10\right)$ or with food availability in the field $\left(F_{(1,954)}=2.42, P=0.17\right)$. Given the similarity between the lab and field data sets, we used the components obtained from the field PCA to construct component scores separately for the field and lab datasets as described below (see Rotenberry and Wiens 1998 for similar methods). To standardize among rate and duration variables, we converted all data to $z$ scores (with a mean of zero and standard deviation of one); we then constructed component scores using unit $( \pm 1)$ component score coefficients for the variables with loadings $>0.5$ (Table 1) and used the component scores for subsequent analyses. We switched the signs of the coefficients for Component 2 (dominance) because the component had negative loadings.

To determine whether low- and high-food-availability sites differed in mating strategies, we performed analyses of variance (ANOVAs) on the field component scores, employing models with a random-effects site term nested within drainage system and site food availability and fixedeffects site food availability and drainage system terms. To examine the influence of time of day, male and female density, sex ratio $[m /(m+f)]$, and light level, we entered each of these covariates into the ANOVA model separately, correcting for multiple tests as noted in the text and tables.

We standardized data from experiments I and II of the common garden experiment to control for differences between them in factors such as the mean age of males and light conditions. This standardization could not have biased the results because of the way in which we carried out the ANOVA; that is, because sites were nested within drainage and different drainages were included in the two lab studies. To construct lab component scores, we performed an ANOVA with experiment (I or II) as the sole factor, taking residuals on the experiment to standardize between lab experiments, and added the overall mean (both experiments combined) to each residual to make the results more comparable to field values. We then constructed the component scores as described above. The subsequent ANOVA models included a random-effects site term nested within drainage system and food availability and a randomeffects male group (the group of three males tested together) term. The model also included fixed-effects site food availability and drainage system terms. Analyses of covariance including male standard length (distance from

Table 3 Analysis of variation in male guppy mating behavior in the field as a function of site, drainage system, and site food availability

\begin{tabular}{llcr}
\hline & $\begin{array}{l}\text { Component 1 } \\
\text { (courtship vs foraging) }\end{array}$ & Component 2 (dominance) & $\begin{array}{c}\text { Component 3 (competition vs } \\
\text { searching for mates) }\end{array}$ \\
\hline Site (drainage system, site food availability) & $4.35_{(6,952)} ; 0.0002$ & $14.30_{(6,917)} ;<0.0001$ & $3.26_{(6,954)} ; 0.004$ \\
Drainage system & $0.20_{(1,952)} ; 0.67$ & $1.12_{(1,917)} ; 0.33$ & $10.14(1,954) ; 0.019$ \\
Site food availability & $2.76_{(1,952)} ; 0.15$ & $1.06_{(1,917)} ; 0.34$ & $8.17_{(1,954)} ; 0.028$ \\
Drainage system $\times$ site food availability & $2.49_{(1,952)} ; 0.17$ & $0.30_{(1,917)} ; 0.60$ & $0.16_{(1,954)} ; 0.70$ \\
\hline
\end{tabular}

Values are $F_{(\mathrm{df})} ; P$. 


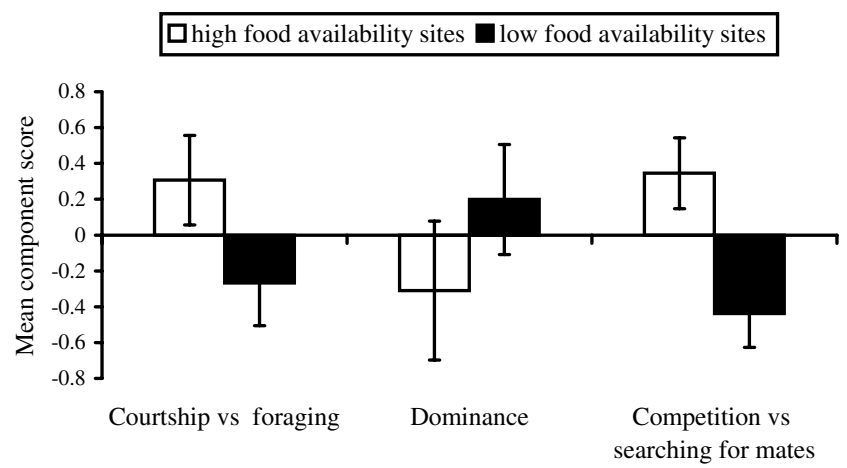

Fig. 2 Mean component scores for male guppies (P. reticulata) from field observations. Bars show square-root transformed, least-squared means $\pm \mathrm{SE}$

the lower jaw to the caudal peduncle) as a covariate revealed no significant relationship between length and the component scores (all $P>0.24$ ), so length was not included in the final models.

For the diet experiment, we reanalyzed data from Kolluru and Grether (2005) by constructing the component scores as described above and performing subsequent ANOVAs employing a model with site food availability and lab food level as main effects. The model also included two random-effects terms: site nested within site food availability and male group (the group of three males tested together) nested within site and food level.

\section{Results}

Field observations

The ten sites varied in mean levels of all three components (Table 3). Males in high-food-availability sites had higher scores for Component 3 (competition vs searching for mates) than males in low-food-availability sites (Table 3; Fig. 2), indicating that males in the high-food-availability sites invested relatively more effort into aggressively competing for females. There were no differences between low- and high-food-availability sites for the other two components. The effort that males invested into courtship at the expense of foraging (Component 1) varied with time of day; scores for this component were greater early (leastsquares mean $\pm \mathrm{SE}=0.20 \pm 0.17)$ and late in the day $(0.21 \pm$ $0.14)$ than at midday $\left(-0.26 \pm 0.12 ; F_{(2,944)}=3.98, P=\right.$ $0.019)$. The other components did not vary with time of day, and none of the interactions involving time of day was significant (all $P>0.06$ ).

The ten sites differed with respect to male and female density, sex ratio, and light levels during the focal observations (Tables 4, 5). Low-food-availability sites had lower light levels; no other covariates differed between low and high-food-availability sites. We found a positive correlation between population mean scores on Component 1 (courtship vs foraging) and site mean sex ratio $(N=10$, Spearman rho $=0.75, P=0.013)$ and a negative correlation between site mean scores on Component 3 (dominance) and site mean density of females $(N=10$, Spearman rho $=-0.65$, $P=0.043$ ), but none of these correlations was significant after correcting for multiple tests (control of the false discovery rate; Verhoeven et al. 2005; $k=9$ correlations). The other correlations between site mean component scores and light level, sex ratio, and male and female density were not statistically significant (all $P>0.07$ ). We also examined the correlations between site mean component scores in the lab and in the field and found none of these to be statistically significant (all $\mid$ Spearman $\mathrm{rho} \mid<0.54$, all $P>0.10$ ).

Addition of each of the four covariates (male and female density, sex ratio, and light level) to the ANOVA model separately did not substantially alter the contribution of the main effects (site, drainage system, and food availability) to variation in male behavior. Component 1 (courtship vs foraging) decreased with light level (standardized $\beta=-0.16$, $F_{(1,535)}=12.61, P=0.0004$ ), Component 2 (dominance) increased with female density (standardized $\beta=0.10$, $\left.F_{(1,820)}=6.39, P=0.012\right)$ and decreased with sex ratio (standardized $\beta=-0.14, F_{(1,815)}=17.30, P<0.0001$ ), and
Table 4 Variation in environmental factors among the ten sites sampled during field focal observations
Male and female densities are square-root transformed numbers of fish, sex ratio is $m /(m+f)$, and light level is $\log _{10}\left(\mu \mathrm{mol} \mathrm{m} \mathrm{m}^{-2} \mathrm{~s}^{-1}\right)$. Values are mean $\pm \mathrm{SE}$.

\begin{tabular}{|c|c|c|c|c|}
\hline Site & Male density & Female density & Sex ratio & Light level \\
\hline \multicolumn{5}{|l|}{ High food availability } \\
\hline Aqui River & $1.76 \pm 0.08$ & $2.15 \pm 0.08$ & $0.39 \pm 0.02$ & $1.76 \pm 0.06$ \\
\hline Marianne River & $1.64 \pm 0.08$ & $1.93 \pm 0.09$ & $0.43 \pm 0.02$ & $1.44 \pm 0.06$ \\
\hline Paria River & $1.62 \pm 0.09$ & $1.83 \pm 0.10$ & $0.43 \pm 0.02$ & $1.53 \pm 0.07$ \\
\hline Small Crayfish River & $2.55 \pm 0.07$ & $3.29 \pm 0.07$ & $0.39 \pm 0.01$ & $1.46 \pm 0.07$ \\
\hline Quare 1 & $1.92 \pm 0.10$ & $2.88 \pm 0.11$ & $0.31 \pm 0.02$ & $1.33 \pm 0.09$ \\
\hline \multicolumn{5}{|l|}{ Low food availability } \\
\hline Madamas Tributary & $1.55 \pm 0.07$ & $2.61 \pm 0.08$ & $0.28 \pm 0.02$ & $1.25 \pm 0.07$ \\
\hline Marianne Tributary & $1.99 \pm 0.07$ & $2.30 \pm 0.08$ & $0.43 \pm 0.02$ & $1.19 \pm 0.06$ \\
\hline Paria Tributary & $1.41 \pm 0.09$ & $1.90 \pm 0.10$ & $0.36 \pm 0.02$ & $1.23 \pm 0.06$ \\
\hline Large Crayfish River & $1.83 \pm 0.08$ & $3.13 \pm 0.08$ & $0.27 \pm 0.02$ & $1.34 \pm 0.06$ \\
\hline Quare 2 & $1.75 \pm 0.08$ & $2.16 \pm 0.09$ & $0.40 \pm 0.02$ & $0.97 \pm 0.16$ \\
\hline
\end{tabular}


Table 5 Analysis of variation in male and female density, sex ratio, and light level during focal observations as a function of site, drainage system, and food availability

\begin{tabular}{lllll}
\hline & Male density & Female density & Sex ratio & Light level \\
\hline Site & $9.89_{(6,856)} ;<0.0001$ & $19.58_{(6,857)} ;<0.0001$ & $14.50_{(6,852)} ;<0.0001$ & $3.43_{(1,537)} ; 0.003$ \\
Drainage system & $4.57_{(1,856)} ; 0.08$ & $9.01_{(1,857)} ; 0.023$ & $1.03_{(1,852)} ; 0.35$ & $1.82_{(1,537)} ; 0.21$ \\
Site food availability & $2.00_{(1,856)} ; 0.21$ & $0.08_{(1,857)} ; 0.79$ & $0.82_{(1,852)} ; 0.40$ & $10.46_{(1,537)} ; 0.011$ \\
Drainage system $\times$ site food availability & $1.63_{(1,856)} ; 0.25$ & $2.17_{(1,857)} ; 0.19$ & $0.31_{(1,852)} ; 0.60$ & $0.35_{(1,537)} ; 0.57$ \\
\hline
\end{tabular}

Values are $F_{(\mathrm{df})} ; P$.

Component 3 (competition vs searching for mates) increased with male density (standardized $\beta=0.20, F_{(1,855)}=$ 32.04, $P<0.0001$ ), female density (standardized $\beta=0.12$, $F_{(1,856)}=9.75, P=0.002$ ), and sex ratio (standardized $\left.\beta=0.13, F_{(1,851)}=13.59, P=0.0002\right)$. All of these results remained significant after a Bonferroni correction within each component (i.e., for four tests; $\alpha=0.0125$ ).

\section{Common garden experiment}

All three behavioral factors varied significantly among male groups (all $P<0.017)$, and factors $2\left(F_{(1,354)}=8.28\right.$, $P<0.0001)$ and $3\left(F_{(1,354)}=8.57, P<0.0001\right)$ varied among sites. None of the factors varied significantly with site food availability (factor 1: $F_{(1,354)}=0.02, P=0.89$; factor 2 : $F_{(1,354)}=4.32, P=0.06$; factor $\left.3: F_{(1,354)}=1.01, P=0.34\right)$, and none of the other terms in any of the models was significant (all $P>0.06$ ). We performed separate analyses of the two experiments to ensure that the results were not a spurious consequence of combining the two datasets, and found almost identical results; none of the factors varied with site food availability.

\section{Diet experiment}

Males raised on the high food level scored higher on component 2 (dominance) than did males raised on the low food level (Table 6; Fig. 3a-c). All three components showed significant site food availability $\times$ lab food level interactions; for components 1 and 3, this was caused by greater differences between low- and high-food-level groups for males from low-food-availability sites than for males from high-food-availability sites. In other words, the norm of reaction with food intake was greater for males from low-food-availability sites. For the dominance component, the norm of reaction with food intake was greater for males from high-food-availability sites.

\section{Discussion}

We found three independent components of variation in male behavior in the field: (1) courtship versus foraging, (2) dominance interactions, and (3) interference competition versus searching for mates (Table 1; also see Croft et al. 2003). Each of these behavioral components varied among sites but only the third correlated with food availability in the field. Compared with males at low-food-availability sites, males at high-food-availability sites devoted more effort to interference competition (aggressively competing over females) versus searching for mates. This difference between high- and low-food-availability populations disappeared in the common garden experiment, which suggests that it primarily resulted from phenotypic plasticity and not genetic divergence between sites (also see Carroll and Corneli 1999; Foster and Endler 1999). The diet experiment confirmed that food intake increases interference competition relative to mate searching, but this was only true for fish from lowfood-availability sites. Food intake also had a direct positive effect on the rate and intensity of dominance interactions, and the strength of this effect was greater in fish from highfood-availability sites. These results generally support the prediction that males engage in less energetically demanding mating tactics when food is scarce.

Table 6 Analysis of variation in male guppy mating behavior in the lab as a function of site food availability and lab food level

\begin{tabular}{lccc}
\hline & $\begin{array}{l}\text { Component } 1 \\
\text { (courtship vs foraging) }\end{array}$ & Component 2 (dominance) & $\begin{array}{c}\text { Component } 3 \text { (competition vs } \\
\text { searching for mates) }\end{array}$ \\
\hline Site (site food availability) & $11.40_{(2,202)} ;<0.0001$ & $30.98_{(2,202)} ;<0.0001$ & $12.12_{(2,202)} ;<0.0001$ \\
Lab food level & $0.81_{(1,202)} ; 0.37$ & $11.55_{(1,202)} ; 0.001$ & $0.70_{(1,202)} ; 0.40$ \\
Site food availability & $1.27_{(1,202)} ; 0.38$ & $0.007_{(1,202)} ; 0.94$ & $1.09_{(1,202)} ; 0.41$ \\
Site food availability $\times$ lab food level & $4.98_{(1,202)} ; 0.027$ & $15.06_{(1,202)} ; 0.0001$ & $7.56_{(1,202)} ; 0.007$ \\
\hline
\end{tabular}

The male group effect is not shown. Values are $F_{(\mathrm{df})} ; P$. 

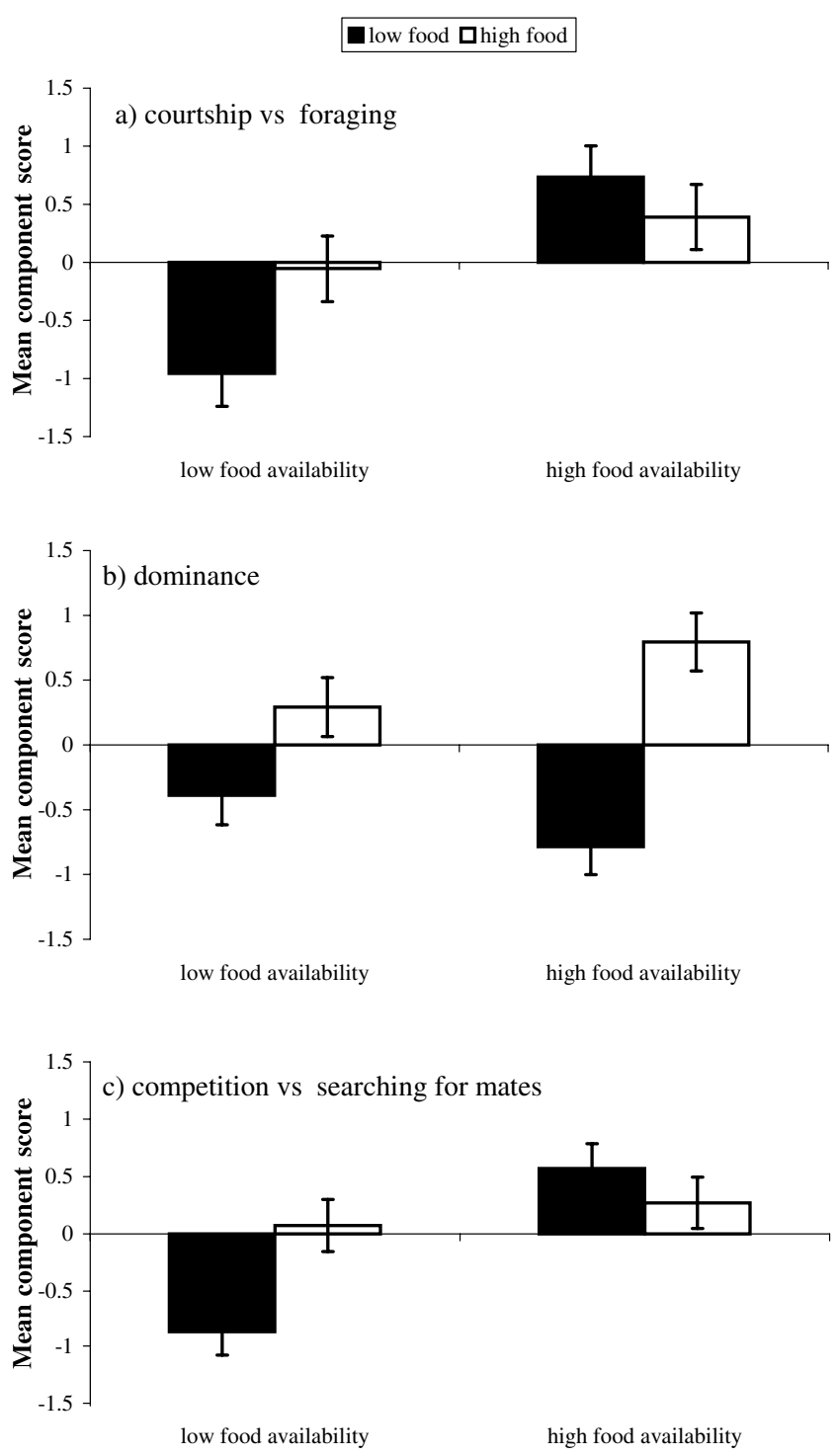

Site food availability

Fig. 3 Mean component scores for Component 1 (courtship versus foraging; a), Component 2 (dominance; b), and Component 3 (competition versus searching for mates; c) for male guppies $(P$. reticulata) from either low- or high-food-availability sites, raised on either low or high food levels. Data are reanalyzed from Kolluru and Grether (2005). Bars show square-root transformed, least-squared means $\pm \mathrm{SE}$

Presumably, the expected payoffs of the different mating tactics exhibited by male guppies are frequency dependent. Our results suggest that the relative success of the interference competition tactic increases as food availability increases, as would be expected if this tactic is more energy-demanding than the alternative tactic of searching for uncourted females. One surprising discrepancy between our field and laboratory results is that dominance interactions were strongly affected by food intake in the laboratory but did not correlate with food availability in the field. It seems likely that food intake affects dominance interactions in the field but that this effect was obscured by countervailing environmental or genetic factors. The common garden experiment showed that populations vary genetically along this behavioral axis, independent of food availability. This could account for the lack of a food availability effect in the field study. Whether better-fed males invest more effort in dominance interactions in the field is an open question.

Other factors besides food intake could potentially be responsible for the association between food availability and interference competition in the field. Ambient light levels and male size at maturity both covary with food availability in the field (Grether et al. 1999, 2001; this study) and could directly affect male behavior. Male size has been suggested to influence courtship and sneak copulation rates (Rodd and Sokolowski 1995; Magellan et al. 2005). Nevertheless, interference competition was not correlated with male size within food level groups in our diet experiment (Kolluru and Grether 2005) or with light levels during focal observations in our field study.

Other studies support a role for food availability in the development or expression of guppy mating tactics. Fraser et al. (2004) found that denying male guppies the opportunity to feed at night reduced their diurnal courtship activity (time spent following females) and suggested that release from predation allows males to forage more at night and thereby court more during the day. Although these authors did not examine male-male interactions or courtship displays, their results suggest that costly mating activity is limited by food intake. In lab studies, hungry male guppies feed before courting females (Abrahams 1993), and hungrier males spend more time foraging than more satiated males, even in the presence of females (Griffiths 1996).

Genetic divergence among sites need not be in the mean value of behaviors but may instead take the form of genotype by environment interactions, so that the degree of response to food intake varies genetically among sites (Rodd and Sokolowski 1995; Carroll and Corneli 1999; Thompson 1999; Hughes et al. 2005). Indeed, comparing mean differences among sites in the lab under ad libitum food conditions may not reveal genetic differences among sites if the differences are in the norm of reaction (Weitere et al. 2004). Our diet experiment, which included guppies from two low- and two high-food-availability sites, revealed that all three behavioral components showed significant interactions between site food availability and lab food level, suggesting that low- and high-foodavailability sites differ in their behavioral norms of reaction to food intake. For the courtship-versus-foraging and competition-versus-searching-for-mates components, the norms of reaction were steeper for males from low-food- 
availability sites (Fig. 3). This may be due to greater variability in food availability in low-food-availability sites (see below), which is expected to favor greater flexibility (reviewed by Komers 1997). If the benefits of behavioral plasticity are reduced in high-food-availability sites, for example because retaining the ability to assess food intake is not necessary when food availability is consistently high, then plasticity is expected to be reduced (Komers 1997; DeWitt et al. 1998). Similar variation in the degree of plasticity among guppy populations was described by Rodd and Sokolowski (1995) and Rodd et al. (1997): males from high-predation sites were less plastic in their mating behavior and in some life history traits than males from low-predation sites. Interestingly, low-predation sites usually have lower food availability than high-predation sites (Reznick et al. 2001), so that the greater flexibility in these sites may be due to food availability differences rather than to predation level differences (in our study, predation and food availability were not confounded).

What has prevented the mean levels of male tactics from diverging genetically along the food availability gradient? A logical explanation is that gene flow along the gradient has prevented local adaptation. This explanation seems unlikely, however, because the sites included in this study are separated by multiple dispersal barriers and have diverged genetically in female mate preferences (Grether 2000; Grether et al. 2005) and male coloration (Grether 2000; Grether and Kolluru, unpublished data). Moreover, we did find evidence for genetic differentiation in behavior among sites in the current study (note significant site terms in Table 6; also see Kolluru and Grether 2005). The explanation we favor is that the plastic responses of male mating tactics to food intake (as revealed by the diet experiment; Kolluru and Grether 2005) are evolved norms of reaction that reduce divergent selection along the food availability gradient. For this explanation to make sense, food availability would have to vary sufficiently within sites for selection to maintain the norms of reaction. Food availability does vary between pools within streams (Grether et al. 2001) and can change rapidly when trees fall and create temporary gaps in the forest canopy (Grether and Kolluru, unpublished data). Floods may also cause transient changes in food availability either by reducing the densities of guppies or reducing algal standing crops (Grether et al. 2001). Thus, it seems plausible that this is a case of adaptive plasticity reducing genetic divergence between populations. Our finding that two of the three behavioral components (courtship versus foraging and competition versus mate searching) were more strongly influenced by food intake in fish derived from low-foodavailability sites is consistent with the hypothesis that the reaction norms are maintained by selection, to the extent that food availability is more stable (or above some energetic threshold) at high-food-availability sites. Tree falls have a larger (positive) effect on algae production in low-food-availability streams (our personal observation and unpublished data). Floods tend to have a larger impact on high-food-availability streams, but because algal standing crops and guppy densities are both reduced, food availability is not greatly affected by floods (Grether et al. 2001).

Light conditions are known to influence guppy reproductive behavior (Long and Rosenqvist 1998; Gamble et al. 2003), presumably because increasing light levels increase the perceived risk of predation (reviewed by Houde 1997). In our study, courtship occurred at a higher rate early and late in the day than at midday and decreased with light level within sites, indicating that males perform courtship displays when they are less conspicuous to potential predators, as first described by Endler (1987) using guppies in artificial streams. This pattern likely occurs because guppy color patterns are most conspicuous to predators at midday and under high light conditions (Endler 1987). Although our sites are subject to low fish predation intensity, they contain $R$. hartii and freshwater prawns (Macrobrachium crenulatum; Endler 1978; Rodd and Reznick 1991; Millar et al. 2006) and may be at risk from visually orienting aerial predators (Endler 1978; Templeton and Shriner 2004).

In many species, the success of mating tactics is influenced by male density and operational sex ratio (Carroll 1993; Quinn et al. 1996; Mills and Reynolds 2003; Lodé et al. 2004), and aggressive mating tactics may be employed more frequently when the sex ratio is more male biased (reviewed by Jirotkul 1999a). In guppies, sneak copulations increase (Evans and Magurran 1999; but see Jirotkul 1999a), courtship displays decrease (Jirotkul 1999a; Evans and Magurran 1999), and male-male competition increases (Jirotkul 1999a; Price and Rodd (2006) as the sex ratio becomes more male biased. Employing much higher densities than those we observed in the field, Jirotkul (1999b) found that aggressive competition also increased with male density in the lab.

Consistent with these observations, we found that males spent more time competing when sex ratios were more male biased and with increasing male density. In contrast, dominance interactions appeared to be more common when competition for females was least intense. Within sites, dominance interactions increased with female density and decreased with sex ratio, suggesting that it may be more profitable for males to spend time establishing and maintaining dominance hierarchies when competition for females is less intense. These results also emphasize that competition and dominance probably serve different purposes for male guppies (Kolluru and Grether 2005). Dominance interactions, which involve (sometimes prolonged) fights between males away from females, are likely 
to be involved in establishing long-term dominance hierarchies among males and may only occur when females are abundant and males can afford to spend time in prolonged interactions with each other. Competition, which involves directly fighting to acquire or maintain access to females, appears instead to be important in the shorter term and may be a tactic better employed when competition for females is intense.

The sex ratios we observed were consistent with those obtained by Pettersson et al. (2004). Their snapshot survey of 11 guppy populations revealed that sex ratios departed significantly from 50:50 in most cases, and that most sites were female biased. It is important to note that because we did not determine the receptivity of females in the field, we could not measure the true operational sex ratio (Emlen and Oring 1977). Most female guppies are not sexually receptive at any given time; fewer than $10 \%$ respond positively to male displays (Magurran and Seghers 1994). Therefore, it is likely that we overestimated the degree to which operational sex ratios were female biased.

Whether male-male competition is important for guppies, and indeed whether it even occurs in the wild, has been the subject of debate (Farr 1975, 1989; Luyten and Liley 1991; Kodric-Brown 1992, 1993; Houde 1997). Recent lab studies have confirmed that males employ aggressive mating tactics (Jirotkul 1999a,b; Kelly and Godin 2001; Kolluru and Grether 2005; Price and Rodd 2006) and suggest that more aggressive males may enjoy higher mating success (Kodric-Brown 1993; Price and Rodd 2006). We commonly observed aggression in the context of mating in the field at sites ranging from small, isolated pools with high guppy densities to larger streams with fastflowing currents and low guppy densities. Although males move among pools (Croft et al. 2003), we sometimes resighted males on multiple visits. At the Marianne Tributary (see Fig. 1 legend), we witnessed rudimentary territorial defense of an area of the stream, a behavior commonly seen in other poeciliid species (reviewed by Farr 1989) and in foraging guppies (Magurran and Seghers 1991). Male guppies remember the individual identities of others and use this information in social contexts (Dugatkin and Sargent 1994; Dosen and Montgomerie 2004). Dominance hierarchies based on prior information gained by males about each other (e.g., Earley et al. 2003), which may be necessary for aggression to influence reproductive success (Farr 1989), may therefore occur in some populations. Recently, Price and Rodd (2006) demonstrated that male guppies unfamiliar with each other are more aggressive than familiar males, presumably because unfamiliar males are in the process of establishing dominance relationships.

Our study emphasizes that variation in guppy mating behavior along food availability gradients is a complex mixture of behavioral plasticity, genetic divergence, and genotype by environment interactions (see also Rodd and Sokolowski 1995; Houde 1997). Phenotypic plasticity such as that we have observed is important because it may reduce selection along food availability gradients (Price et al. 2003; West-Eberhard 1989). In addition, the behavioral differences we describe between low- and high-foodavailability sites are similar to those found by some authors comparing low- and high-predation sites (Endler 1995; Houde 1997). Because high-predation localities tend to be more open, with higher light levels and greater primary productivity, than low-predation localities (Reznick et al. 2001; Grether et al. 2001), at least some of the behavioral variation along predation gradients may be attributable to concomitant variation in food availability (Magurran and Seghers 1994).

Acknowledgment We are grateful to Randy Tashjian and Wendy Mayea for helping to transcribe data from audiotapes, and C. St. Mary and two anonymous reviewers for their comments on an earlier version of the manuscript. In Trinidad, we thank the Sinanan family for housing accommodations, the Ministry of Food Production, Marine Exploitation, Forestry, and the Environment for permits to collect guppies, and the Water and Sewage Authority for permission to work in the Quare drainages. This study was supported by National Science Foundation grants IBN-0001309 to GFG and IBN-0130893 to GFG and GRK. The experiments comply with current US laws.

\section{References}

Abrahams MV (1993) The trade-off between foraging and courting in male guppies. Anim Behav 45:673-681

Belovsky GE, Slade JB, Chase JM (1996) Mating strategies based on foraging ability: an experiment with grasshoppers. Behav Ecol 7:438-444

Blanckenhorn WU, Preziosi RF, Fairbairn DF (1995) Time and energy constraints and the evolution of sexual size dimorphism - to eat or to mate? Evol Ecol 9:369-381

Brockmann HJ (2001) The evolution of alternative strategies and tactics. Adv Study Behav 30:1-51

Carroll SP (1993) Divergence in male mating tactics between two populations of the soapberry bug: I. guarding versus nonguarding. Behav Ecol 4:156-164

Carroll SP, Corneli PS (1995) Divergence in male mating tactics between two populations of the soapberry bug: II. genetic change and the evolution of a plastic reaction norm in a variable social environment. Behav Ecol 6:46-56

Carroll SP, Corneli PS (1999) The evolution of behavioral norms of reaction as a problem in ecological genetics: theory, methods, and data. In: Foster SA, Endler JA (eds) Geographic variation in behavior. Oxford University Press, New York, pp 52-68

Croft DP, Albanese B, Arrowsmith BJ, Botham M, Webster M, Krause J (2003) Sex-biased movement in the guppy (Poecilia reticulata). Oecologia 137:62-68

DeWitt TJ, Sih A, Wilson DS (1998) Costs and limits of phenotypic plasticity. Trends Ecol Evol 13:77-81

Dosen LD, Montgomerie R (2004) Mate preferences by male guppies (Poecilia reticulata) in relation to the risk of sperm competition. Behav Ecol Sociobiol 55:266-271 
Dugatkin LA, Sargent RC (1994) Male-male association patterns and female proximity in the guppy, Poecilia reticulata. Behav Ecol Sociobiol 35:141-145

Dussault GV, Kramer DL (1981) Food and feeding behavior of the guppy, Poecilia reticulata (Pisces: Poeciliidae). Can J Zool 59:684-701

Earley RL, Tinsley M, Dugatkin LA (2003) To see or not to see: does previewing a future opponent affect the contest behavior of green swordtail males (Xiphophorus helleri)? Naturwissenschaften 90:226-230

Emlen ST, Oring LW (1977) Ecology, sexual selection, and the evolution of mating systems. Science 197:215-223

Endler JA (1978) A predator's view of animal color patterns. Evol Biol 11:319-364

Endler JA (1987) Predation, light intensity and courtship behavior in Poecilia reticulata (Pisces: Poeciliidae). Anim Behav 35:1376-1385

Endler JA (1995) Multiple-trait coevolution and environmental gradients in guppies. Trends Ecol Evol 10:22-29

Evans JP, Magurran AE (1999) Male mating behavior and sperm production characteristics under varying sperm competition risk in guppies. Anim Behav 58:1001-1006

Farr JA (1975) The role of predation in the evolution of social behavior of natural populations of the guppy, Poecilia reticulata (Pisces: Poeciliidae). Evolution 29:151-158

Farr JA (1989) Sexual selection and secondary sexual differentiation in poeciliids: determinants of male mating success and the evolution of female choice. In: Meffe GK, Snelson FF (eds) Ecology and evolution of livebearing fishes (Poeciliidae). Prentice Hall, Englewood Cliffs, NJ, pp 91-123

Foster SA, Endler JA (1999) Thoughts on geographic variation in behavior. In: Foster SA, Endler JA (eds) Geographic variation in behavior. Oxford University Press, New York, pp 287-305

Fraser DF, Gilliam JF, Akkara JT, Albanese BW, Snider SB (2004) Night feeding by guppies under predator release: effects on growth and daytime courtship. Ecology 85:312-319

Gamble S, Lindholm AK, Endler JA, Brooks R (2003) Environmental variation an the maintenance of polymorphism: the effect of ambient light spectrum on mating behavior and sexual selection in guppies. Ecol Lett 6:463-472

Grether GF (2000) Carotenoid limitation and mate preference evolution: a test of the indicator hypothesis in guppies (Poecilia reticulata). Evolution 54:1712-1724

Grether GF, Hudon J, Millie DF (1999) Carotenoid limitation of sexual coloration along an environmental gradient in guppies. Proc R Soc Lond B 266:1317-1322

Grether GF, Millie DF, Bryant MJ, Reznick DN, Mayea W (2001) Rain forest canopy cover, resource availability, and life history evolution in guppies. Ecology 82:1546-1559

Grether GF, Kolluru GR, Rodd FH, de la Cerda J, Shimazaki K (2005) Carotenoid availability affects the development of a colour-based mate preference and the sensory bias to which it is genetically linked. Proc R Soc Lond B 272:2181-2188

Griffiths SW (1996) Sex differences in the trade-off between feeding and mating in the guppy. J Fish Biol 48:891-898

Gross MR (1996) Alternative reproductive strategies and tactics: diversity within sexes. Trends Ecol Evol 11:92-98

Houde AE (1997) Sex, color, and mate choice in guppies. Princeton University Press, New Jersey

Houde AE, Endler JA (1990) Correlated evolution of female mating preferences and male color patterns in the guppy Poecilia reticulata. Science 248:1405-1408

Hughes KA, Rodd FH, Reznick DN (2005) Genetic and environmental effects on secondary sex traits in guppies (Poecilia reticulata). J Evol Biol 18:35-45

Jirotkul M (1999a) Operational sex ratio influences female preference and male-male competition in guppies. Anim Behav 58:287294
Jirotkul M (1999b) Population density influences male-male competition in guppies. Anim Behav 58:1169-1175

Jirotkul M (2000) Male trait distribution determined alternative mating tactics in guppies. J Fish Biol 56:1427-1434

Kelly CD, Godin J-GJ (2001) Predation risk reduces male-male sexual competition in the Trinidadian guppy (Poecilia reticulata). Behav Ecol Sociobiol 51:95-100

Kodric-Brown A (1992) Male dominance can enhance mating success in guppies. Anim Behav 44:165-167

Kodric-Brown A (1993) Female choice of multiple male criteria in guppies: interacting effects of dominance, coloration and courtship. Behav Ecol Sociobiol 32:415-420

Kolluru GR, Grether GF (2005) The effects of resource availability on alternative mating tactics in guppies (Poecilia reticulata). Behav Ecol 16:294-300

Kolluru GR, Grether GF, South SH, Dunlop E, Cardinali A, Liu L, Carapiet A (2006) The effects of carotenoid and food availability on resistance to a naturally occurring parasite (Gyrodactylus turnbulli) in guppies (Poecilia reticulata). Biol J Linn Soc 89:301-309

Komers PE (1997) Behavioral plasticity in variable environments. Can J Zool 75:161-169

Lodé T, Holveck M-J, Lesbarreres D, Pagano A (2004) Sex-biased predation by polecats influences the mating system of frogs. Proc R Soc Lond B 271:S399-S401

Long KD, Rosenqvist G (1998) Changes in male guppy courting distance in response to a fluctuating light environment. Behav Ecol Sociobiol 44:77-83

Luyten PH, Liley NR (1991) Sexual selection and competitive mating success of male guppies (Poecilia reticulata) from four Trinidad populations. Behav Ecol Sociobiol 28:329-336

Magellan K, Pettersson LB, Magurran AE (2005) Quantifying male attractiveness and mating behavior through phenotypic size manipulation in the Trinidadian guppy, Poecilia reticulata. Behav Ecol Sociobiol 58:366-374

Magurran AE, Seghers BH (1991) Variation in schooling and aggression amongst guppy (Poecilia reticulata) populations in Trinidad. Behaviour 118:214-234

Magurran AE, Seghers BH (1994) Sexual conflict as a consequence of ecology: evidence from guppy, Poecilia reticulata, populations in Trinidad. Proc R Soc Lond B 225:31-36

Millar NP, Reznick DN, Kinnison MT, Hendry AP (2006) Disentangling the selective factors that act on male color in wild guppies. Oikos 113:1-12

Mills SC, Reynolds JD (2003) Operational sex ratio and alternative reproductive behaviors in the European bitterling, Rhodeus sericeus. Behav Ecol Sociobiol 54:98-104

Moczek AP, Emlen DJ (1999) Proximate determination of male horn dimorphism in the beetle Onthophagus taurus (Coleoptera: Scarabaeidae). J Evol Biol 12:27-37

Pettersson LB, Ramnarine IW, Becher SA, Mahabir R, Magurran AE (2004) Sex ratio dynamics and fluctuating selection pressures in natural populations of the Trinidadian guppy, Poecilia reticulata. Behav Ecol Sociobiol 55:461-468

Plaistow S, Siva-Jothy MT (1996) Energetic constraints and male mate-securing tactics in the damselfly Calopteryx splendens xanthostoma (Charpentier). Proc R Soc Lond B 263:1233-1239

Price AC, Rodd FH (2006) The effect of social environment on malemale competition in guppies (Poecilia reticulata). Ethology 112:22-32

Price TD, Qvarnstrom A, Irwin DE (2003) The role of phenotypic plasticity in driving genetic evolution. Proc R Soc Lond B 270:1433-1440

Quinn TP, Adkison MD, Ward MB (1996) Behavioral tactics of male sockeye salmon (Oncorhynchus nerka) under varying operational sex ratios. Ethology 102:304-322 
Reyer H-U, Fischer W, Steck P, Nabulon T, Kessler P (1998) Sexspecific nest defense in house sparrows (Passer domesticus) varies with badge size of males. Behav Ecol Sociobiol 42:93-99

Reynolds JD, Gross MR, Coombs J (1993) Environmental conditions and male morphology determine alternative mating behavior in Trinidadian guppies. Anim Behav 45:145-152

Reznick D, Butler MJ IV, Rodd H (2001) Life-history evolution in guppies. VII. The comparative ecology of high- and lowpredation environments. Am Nat 157:126-140

Rodd FH, Reznick DN (1991) Life-history evolution in guppies.3: the impact of prawn predation on guppy life histories. Oikos 62:13-19

Rodd FH, Sokolowski MB (1995) Complex origins of variation in the sexual behavior of male Trinidadian guppies, Poecilia reticulata: interactions between social environment, heredity, body size and age. Anim Behav 49:1139-1159

Rodd FH, Reznick DN, Sokolowski MB (1997) Phenotypic plasticity in the life history traits of guppies: responses to social environment. Ecology 78:419-433

Rotenberry JT, Wiens JA (1998) Foraging patch selection by shrubsteppe sparrows. Ecology 79:1160-1173

Shuster SM, Wade MJ (2003) Mating systems and strategies. Princeton University Press, Princeton
Tabachnick BG, Fidell LS (2001) Using multivariate statistics, 4th edn. Allyn and Bacon, Needham Heights, MA

Thompson DB (1999) Different spatial scales of natural selection and gene flow: the evolution of behavioral geographic variation and phenotypic plasticity. In: Foster SA, Endler JA (eds) Geographic variation in behavior. Oxford University Press, New York, pp 52-68

Templeton CN, Shriner WM (2004) Multiple selection pressures influence Trinidadian guppy (Poecilia reticulata) antipredator behavior. Behav Ecol 4:673-678

Verhoeven KJF, Simonsen KL, McIntyre LM (2005) Implementing false discovery rate control: increasing your power. Oikos 108:643-647

Weitere M, Tautz D, Neumann D, Steinfartz S (2004) Adaptive divergence vs. environmental plasticity: tracing local genetic adaptation of metamorphosis traits in salamanders. Mol Ecol 13:1665-1677

West-Eberhard MJ (2003) Developmental Plasticity and Evolution. Oxford University Press, Oxford

Winge O (1937) Succession of broods in Lebistes. Nature 140:467

Zuk M, Rotenberry JT, Simmons LW (1998) Calling songs of field crickets (Teleogryllus oceanicus) with and without phonotactic parasitoid infection. Evolution 52:166-171 